\title{
Making large gravity irrigation systems perform
}

\author{
G. Spencer \\ Business Development Manager, International, Rubicon Systems, \\ Australia
}

\begin{abstract}
By 2050 the world's population will increase by an estimated 50\%. Most of the increased food demands will have to come from productivity improvements in existing irrigated agricultural areas. These improvements will need to be achieved with less water and less farm land because of the competition from urbanization, industrialization, the need to provide water for environmental purposes and to respond to climate change impacts. Therefore, the challenge facing us is to make existing irrigation systems more efficient and productive to better utilize the shrinking agricultural land and water resources.

In south-eastern Australia, severe water shortages brought about by a prolonged 11 year drought sequence has spurred a lot of innovative thinking about how to use the limited available water more efficiently in irrigation and, at the same time, improving the performance of irrigation systems.

A higher level of technological investment in the modernization of large unlined, gravity fed irrigation systems in the south-eastern state of Victoria has resulted in increases in efficiency from about $70 \%$ up to about $90 \%$ - a remarkable outcome. In Victoria, the water saved is being reallocated equally between urban and industrial users, the environment and to existing farmers to improve their security of supply.

The investment required is a mix of both hardware and software involving remotely controlled gates, accurate water measuring devices, Supervisory Control and Data Acquisition (SCADA) and system management software. This investment, combined with modelling and control technologies, has resulted in the delivery of significantly improved services to irrigators in terms of equity, reliability and flexibility, and huge improvements in the management capability and performance of existing large-scale irrigation systems.
\end{abstract}


Keywords: modernization, SCADA, channel control technology, accurate water measurement, improved performance and efficiency, water resource savings.

\section{Introduction}

South eastern Australia is in the grip of an unprecedented 11 year drought sequence, which has significantly reduced the availability of water in the large inter-state Murray-Darling River basin system. Annual River flows are at all time low levels and since 1997 have averaged 44\% less than the long term average (1891-1997) [2]. The state (provincial) government of Victoria (GoV) is facing a challenging and constantly evolving situation of: (i) increased water demands from a growing population; (ii) continued reliance on reliable water supplies to meet agricultural, industrial, tourism and recreational demands; (iii) the need to provide water for environmental purposes to the increasingly stressed natural environment; (iv) the continuing drought sequence, now in its twelfth year; and (v) climate change predictions of even less rain and higher temperatures. Faced with this situation, the government has formulated and is implementing a state water plan entitled "Securing Our Water Future Together" [2] with the over-arching objective of improving the use and management of the state's diminishing water resources on a sustainable basis.

The six priority elements of the state water plan are: (i) improved water allocation framework; (ii) restoring rivers and aquifers to sustainable levels; (iii) smarter use of irrigation water; (iv) smarter use of urban and industrial water; (v) water pricing for sustainability; and (vi) innovative and accountable management of the water sector. This paper details the GoV's third priority area - the smarter use of irrigation water [2].

\section{Improving the efficiency and productivity of irrigation}

Like anywhere in the world, irrigation in Victoria generates substantial and growing economic and regional benefits and uses the largest share of available water. Water consumption in all sectors state-wide is about 7 Billion cubic metres (BCM) per annum, with the irrigation sector using about $77 \%$ of this figure. Figure 1 shows the consumptive uses of water by sectors (1996-1997).

Compared to other sectors, irrigation uses its large share of water relatively inefficiently. The key challenges for the GoV to bring about the smarter use of water for irrigation are to: (i) ensure that the irrigation sector will prosper in a competitive, global environment by moving water to higher-value uses through the enhancement of water trading and water markets; (ii) reconfigure irrigation infrastructure and adopt world best practice innovations and new technology through large scale capital investment in modernization programs; and (iii) adjust to changing community expectations about the environment by improving on-farm water use, reducing losses in distribution systems and allocating water to the environment.

The outcomes expected are: (i) a confident, profitable and adaptable irrigation sector that generates wealth for regional communities and Victoria; 


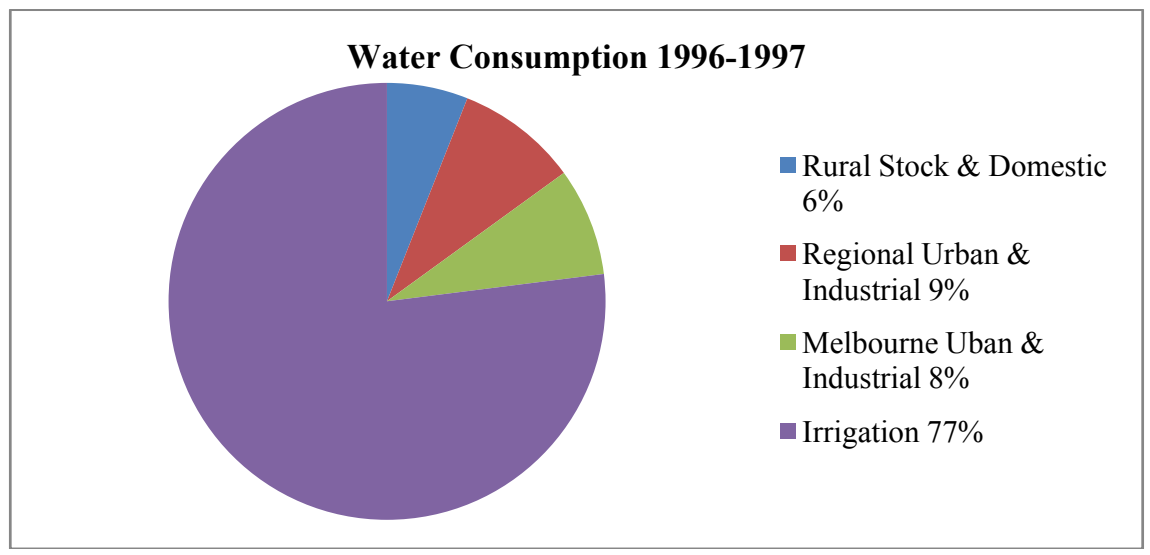

Figure 1: Water consumption in Victoria by major consumer group [3].

(ii) an increase in the efficiency of irrigation systems across the state of $25 \%$ by 2020; (iii) responsive and flexible irrigation supply systems that are effective and economic; (iv) lower salinity and nutrient side-effects of irrigation; and (v) the freeing up water to better meet future urban, industrial environmental needs.

Many of these expected outcomes will be delivered through a major government initiative and investment program, the Northern Victoria Irrigation Renewals Project (NVIRP), that will bring about increased efficiency of use of irrigation water and greatly improved irrigation water services to customers in a far more responsive, effective and economical manner.

\section{The Northern Victoria Irrigation Renewals Project (NVIRP)}

The NVIRP [4] is an AU\$2bn, 2 stage program with the primary objective of improving water distribution efficiencies in order to save a total of 425 $\mathrm{MCM}$ /annum of irrigation water $(225 \mathrm{MCM}$ /annum in stage 1 and a further 200 $\mathrm{MCM}$ /annum in stage 2). The stage 1 savings will be shared equally between Melbourne urban and industrial users, the environment and irrigators. Stage 2 water savings will be shared equally between the environment and irrigators. In addition, the project aims to greatly improve levels of service to farmers and so improve the productivity of irrigation.

The project area (stages 1 and 2) covers about 800,000 ha, involving about 14,000 farms and 6,300 km of publically owned channels, fig. 2 .

\subsection{Unaccounted for water and improved operating efficiency}

Water unaccounted for in open, unlined irrigation systems consist of evaporation, inaccurate metering and outfalls. Outfalls are generally unplanned spills or releases of water that prevent water over-topping of channel banks as a result of poor regulation and control of water flows. Other sources are leakage, 
seepage and losses from natural water courses (rivers and creeks) that are used as part of the water delivery network. The typical percentage of unaccounted for water from each source for the irrigation systems within the NVIRP project area are shown in figure 3.

The typical operating efficiency, from reservoir to farm supply point is about $70 \%$. The NVIRP water savings are generated from a reduction in some of the losses; particularly those associated with inaccurate measurement within irrigation systems and at each farm supply point; better water regulation to

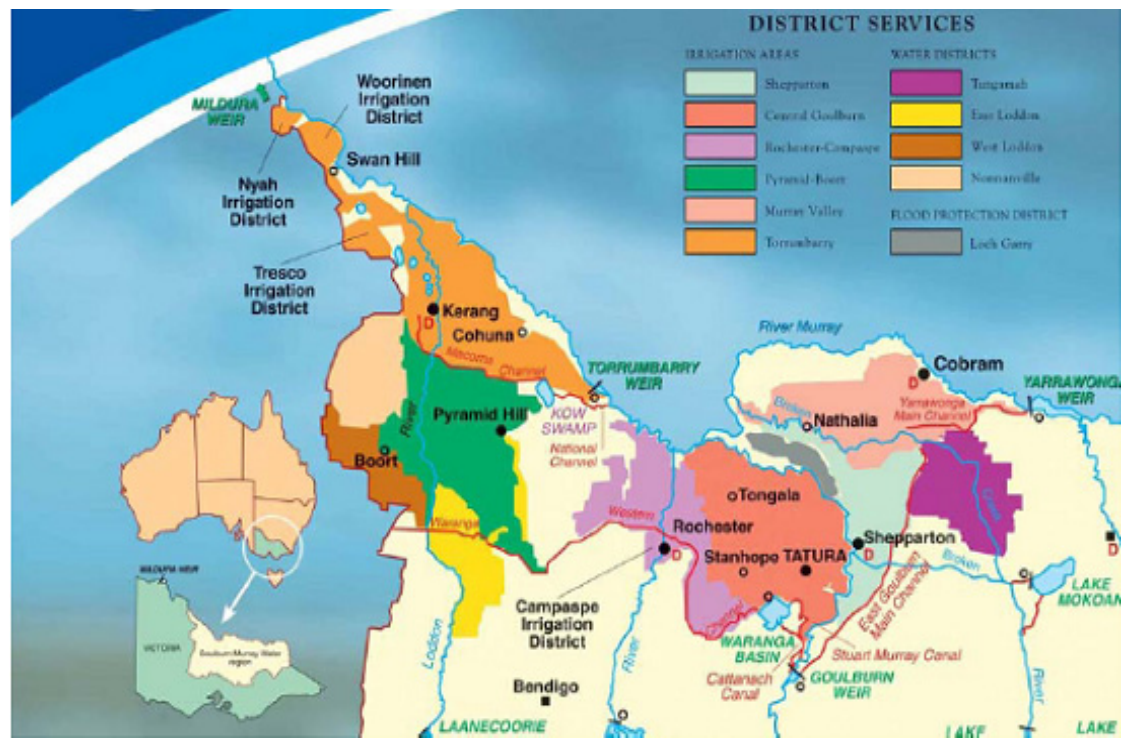

Figure 2: $\quad$ NVIRP project area [4].

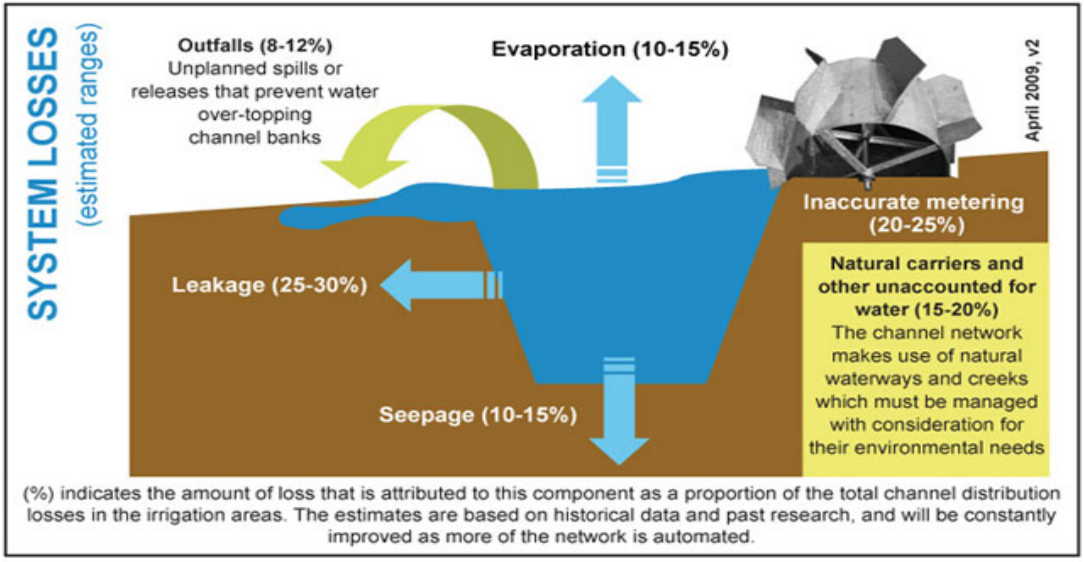

Figure 3: $\quad$ Typical unaccounted for water in irrigation systems [4]. 

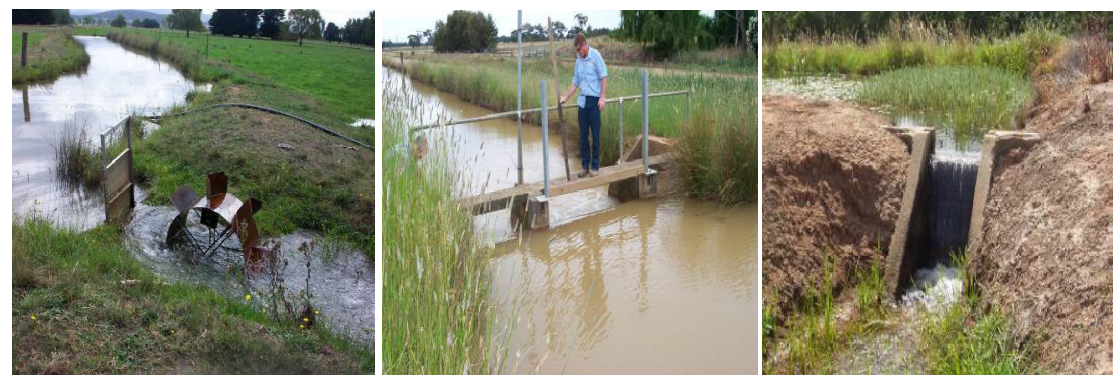

Figure 4: Sources of channel losses. L-R, inaccurate measurement at farm supply point; old timber drop-bar weir type regulator and measuring point manually operated; operational losses resulting in "outfalls".

virtually eliminate operational losses from outfalls; and leakage and seepage through selected lining of channels.

The NVIRP investment program is funding activities that will deliver a stateof-the-art modernized irrigation system and completely transform the existing manually operated, labour intensive, conservatively operated, high water loss system into one that is extraordinarily responsive, flexible, equitable and efficient, enabling irrigators to get water at the flow rate and time they specify. The expected outputs from the investment will be: (i) channel automation with full SCADA capability; (ii) accurate measurement of water at all levels; (iii) reduced leakage and seepage through selected channel lining; (iv) reduced operational losses through enhanced management; and (v) significantly improved water services to customers.

\subsection{Total Channel Control ${ }^{\circledR}(\mathrm{TCC} \circledast)$ technology}

To deliver the expected outcomes, NVIRP is procuring Rubicon Systems Australia's Total Channel Control (TCC $®)$ [5], which is a revolutionary end-toend irrigation canal automation technology that is transforming the inefficient manually operated open canal networks into fully automated, integrated and remotely controlled systems that are achieving demonstrated new benchmark delivery efficiencies of up to $90 \%$ [6].

A breakthrough in both irrigation control and flow measurement, the $\mathrm{TCC}^{\circledR}$ technology provides a system of solar-powered channel regulators and gates, linked through radio telemetry and advanced computer software to enable the whole channel network to operate efficiently, automatically and remotely. Solar power at each gate eliminates the cost of providing mains power to each site. This is particularly important when sites are in remote locations away from the power grid.

\subsubsection{The Rubicon FlumeGate ${ }^{\mathrm{TM}}$}

A fundamental component of $\mathrm{TCC}^{\circledR}$ is Rubicon's unique FlumeGate ${ }^{\mathrm{TM}}$ (fig. 5), which provides accurate measurement and control/regulation of flows at every 
point throughout an entire system, while eliminating manual operation of all water control gates.

Water is measured accurately through each gate for both free over-fall and submerged flow conditions, using the unique flow measurement technology developed by Rubicon and integrated into the design of each gate. Combined with control algorithms and the high level of measurement accuracy at each structure, leakage, seepage and theft losses can be identified and pinpointed more accurately. The comprehensive management information generated by $\mathrm{TCC}^{\circledR}$ is then used as the basis for selective channel lining investment by NVIRP and for routine maintenance and follow up action by the Irrigation Management Authority (IMA). For NVIRP, this improves the efficiency of investment considerably in that it enables just the problem reaches of channels where the greatest losses are occurring to be addressed. Channel lining activities typically involve laying flexible high density polyethylene (HDPE) membrane, $2 \mathrm{~mm}$ thick (fig. 6). Lining involves re-shaping the existing earthen channel before the lining is placed and fencing of channel rights-of-way to exclude cattle from damaging the lining.

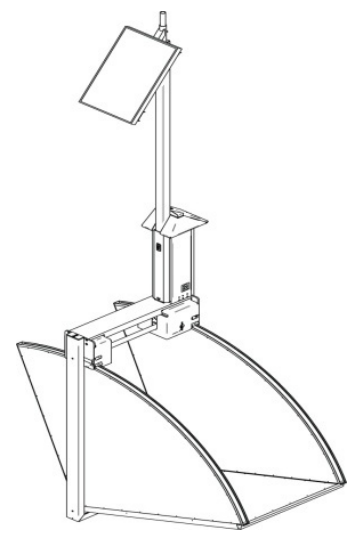

Figure 5: Schematic diagram of a Rubicon FlumeGate TM complete with communications pole, solar panel, electronics module, gear box and drive shaft.

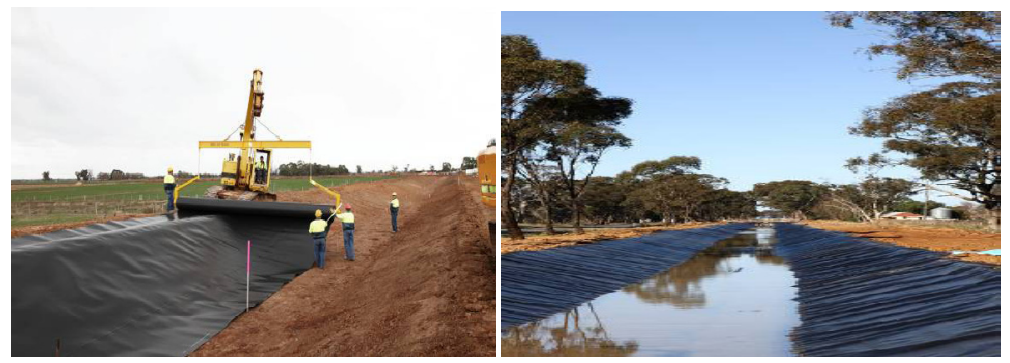

Figure 6: Typical NVIRP channel lining activities. 
Lastly, automatic control of open channels and flow measurement is realizing significant water savings that are being reallocated to urban users (who are funding a significant portion of the project); to distressed river networks; and, to farmers to improve their security of supply. Furthermore, the prevention of outfalls ensures that pollutants such as salt and nutrients do not enter river systems and cause environmental damage.

\subsubsection{Installation of FlumeGates ${ }^{\mathrm{TM}}$}

An advantage of the FlumeGate ${ }^{\mathrm{TM}}$ is the quick installation into existing regulation structures where the concrete is sound, resulting in considerable cost savings through not having to replace the whole structure. Installation can be done in "wet" or "dry" conditions, resulting in minimum disruption to irrigation supplies. Figure 7 below shows gate installations under varying conditions. The right-hand photo shows details of the frame that is attached to the existing structure that then accepts the FlumeGate ${ }^{\mathrm{TM}}$ module. Where a new structure is required, a low cost alternative has been developed using a pre-cast concrete components.

3.2.2.1 Calibration and commissioning Each FlumeGate ${ }^{\mathrm{TM}}$ is ready to "plug and play" as it is calibrated and pre-commissioned at the factory and comes "SCADA ready" with factory set configurations. Each gate has dual redundancy water level sensors incorporated and connected to high precision digital instruments. There is no requirement for commissioning in the field. All that is required is simple accuracy verification and field calibration with no specialist skills required by field staff. Figure 8 shows FlumeGates ${ }^{\mathrm{TM}}$ installed and functional.

\section{Enhanced irrigation management and improved customer services benefits}

While water savings is the primary focus for NVIRP stage 1, the modernized irrigation system is delivering significant new benefits for irrigators and IMA
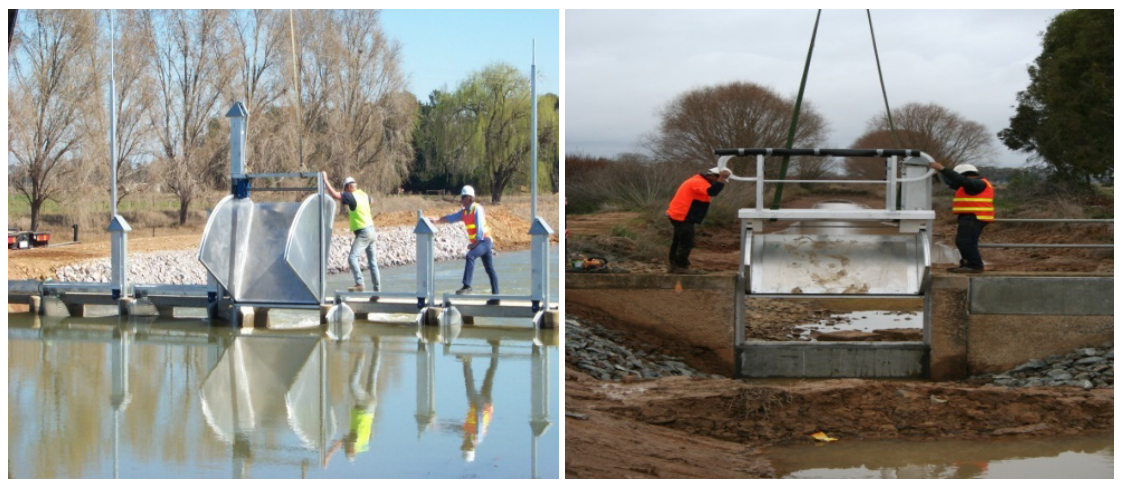

Figure 7: FlumeGate TM installation in "wet and dry" channel conditions. 


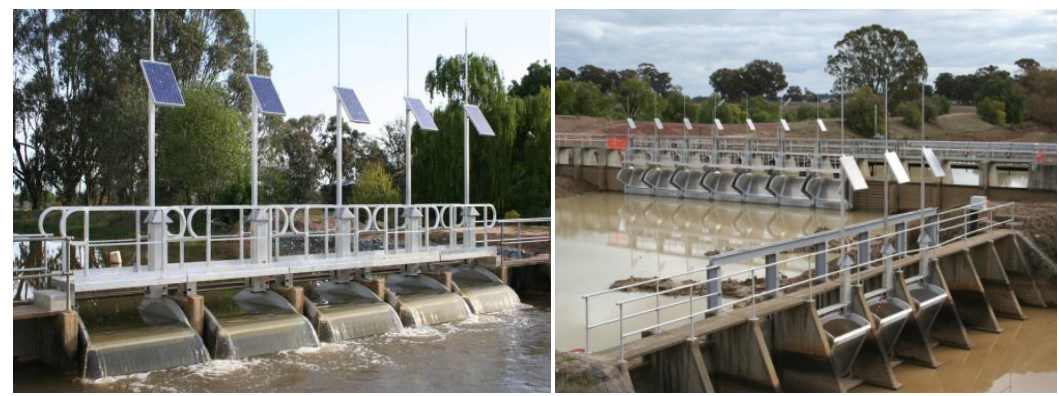

Figure 8: (L-R) New 5 bay regulator and a major regulating and measuring point retro-fitted to existing concrete structures. Note on the right the reduced number of bays required due to enhanced flow characteristics.

water operational managers and staff alike. The investment in stage 1 activities is also laying the foundation for substantial on-farm water savings, which will be the focus of investment under stage 2 .

Modernisation of the irrigation delivery system is the first step in revolutionising how rural water is valued and managed. When completed, the modernized system will provide improved levels of service to customers and a more efficient network for system operators to manage. These benefits are evident from performance data from the 2008/09 irrigation season in areas already modernized. Results, using data from the much enhanced management information systems (MIS) software provided as part of the $\mathrm{TCC}^{\circledR}$ package, clearly show significant improvements in irrigation system performance in key areas, and also to customer service levels.

\subsection{Irrigation system performance and operator benefits}

Modernization is transforming irrigations systems from labour intensive and data deficient to automatic and data rich. The IMA has established a central 24/7 water operations centre to ensure proper operational management using real time data inputs.

\subsubsection{System monitoring and data use}

Monitoring of the old manual systems relies on a large field staff presence for visual inspections and manual non-continuous monitoring. Delays in the collection, transmission and analysis of data result in delayed decision making and response to changing circumstances. By contrast, automation under TCC $^{\circledR}$ provides the opportunity to monitor remotely in real time, collect enormous amounts of data and use computer based decision support systems (DSS) that allow water managers to make timely and informed decisions. In addition, automatic alarming allows immediate response to irregular or emergency operational situations. The ability to properly manage extends down to the point of supply to farms. New remote water meters installed as part of the 
modernization effort now allow the monitoring of service levels at the point of supply to farms and the data gathered allows timely response to customer service issues and problems.

\subsubsection{Water savings through better operational control of channels}

System generated data (fig. 9) shows just how well demand is matched to capacity in a channel operating under TCC®. The graph is a screenshot of management information data for a typical channel outfall (or escape). Instantaneous and cumulative outfall volumes from the channel $(250 \mathrm{ML} / \mathrm{d}$ offtake capacity and $18 \mathrm{~km}$ in length) are shown for the 2008/09 irrigation season. The channel was modernized in June/July 2008 with FlumeGates ${ }^{\text {TM }}$ and operated manually until mid November 2008, when full TCC® was initiated. Cumulative outfalls up until TCC® implementation were 286ML. Outfalls for the remainder of the 2008/09 season (to end April 2009) were just 3ML.

\subsubsection{Reduction in labour and improved worker health and safety}

Automation provides a fundamental change in field level labour requirements for water operations. Labour once used to physically place and remove timber drop bars and open and close doors and valves is now redundant. The role of labour has changed to one of "field monitoring and maintenance". There has also been a significant improvement in occupational health and safety (OH\&S) conditions for workers, with a reduction in work related lost time injuries and improvement in work place safety.

\subsubsection{Consistent supply levels}

Channel supply levels fluctuate as a consequence of traditional manual regulation, resulting in variable flow rates onto farms. This is a constant source of frustration and complaint by farmers. In order to provide a consistent flow rate, customers must manually adjust the flow through their meter to compensate for the varying supply level.

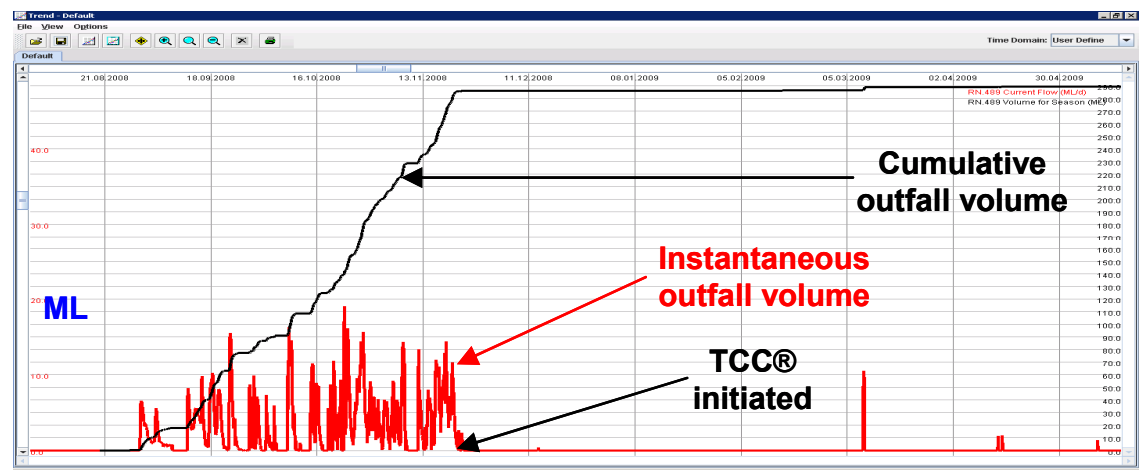

Figure 9: Instantaneous and cumulative outfalls for the CG No 5 channel

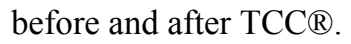




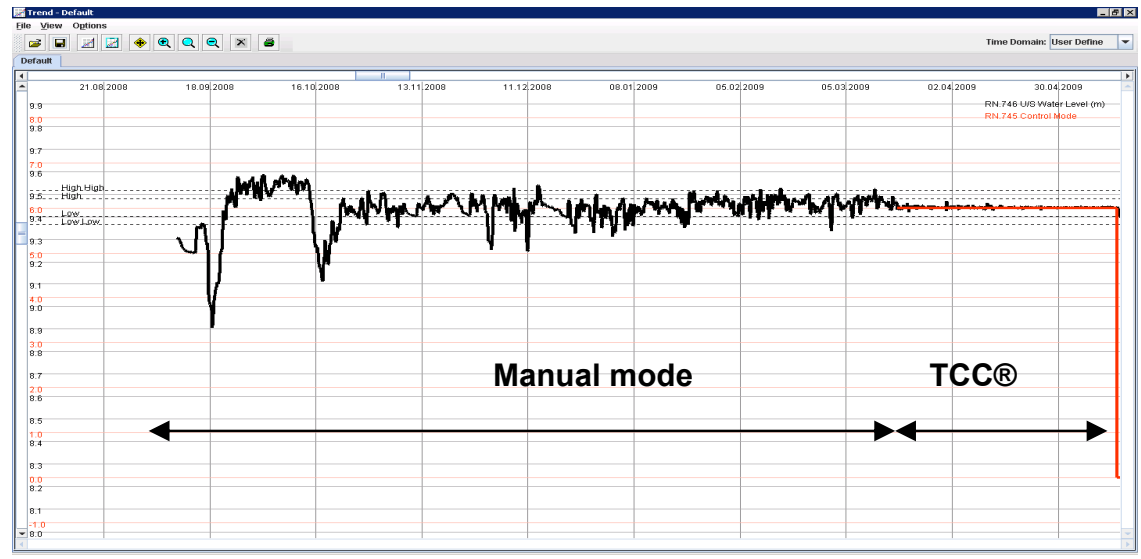

Figure 10: Channel supply level control.

Automation minimises fluctuating supply levels by constantly regulating flows according to demand. FlumeGate ${ }^{\mathrm{TM}}$ regulators operate in unison via Rubicon's software program. Figure 10 demonstrates how TCC $\AA$ provides consistent supply levels compared to operations using traditional manual processes. The FlumeGate ${ }^{\mathrm{TM}}$ installed at this site was controlled manually between September 2008 and mid March 2009 when full TCC® was initiated, resulting in a stable supply level in the pool.

\subsection{Customer services benefits}

Enhanced customer services focuses on improving the flexibility, reliably and equity of irrigation services. The modernized system fundamentally changes the way in which irrigation orders are placed and scheduled and new meters improve the flow rates to farms, resulting in higher volume, shorter duration irrigations. With enhanced operational data and control capabilities, customers are able to make more informed decisions matching the actual crop water requirements onfarm. Orders for water are lodged directly into the irrigation planning database maintained by the IMA [7]. The ordering, scheduling and delivery process is shown in fig. 11. The system is an Interactive Voice Response (IVR) telephone ordering system called WaterLINE, specifically developed by Rubicon Systems for the IMA. Running in parallel with the IVR system is the next generation WEB based water ordering system. This was introduced in 2002, and offers considerable enhancement over the IVR system because of its WEB interface. As of February 2010, over $30 \%$ of all orders for irrigation water are lodged via this enhanced WEB based system. It is proving to be a much simpler and clearer management method for IMA staff and customers alike. The internet based system allows customers to view on-screen, the current and future availability of channel capacity at their point of supply. The customer then selects the best available irrigation time to suit his needs. 


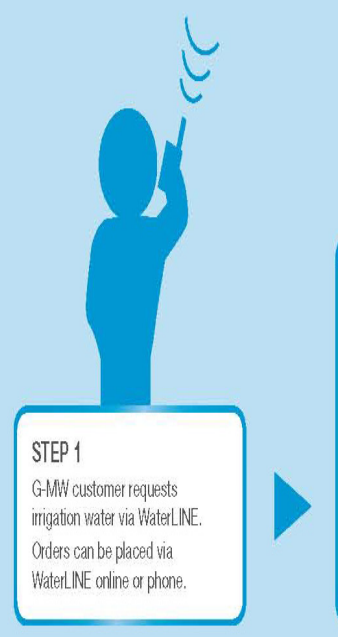

\section{STEP2}

If capacity in channed is avalable, the water order is entered into Irigation Flanning Modde (IIPM) system automatically. IFH checks the order against the balance in the customers Allocation Bank Account ( $\mid \mathrm{BA}$ ). If sulficient allociation is avalable, it accepts the order. IPM identifies the chamel system, automated channel regulators and service points imetersi that will need to make adjustments to meet the request (order), and sends out electronic instructions via radio telemetry.

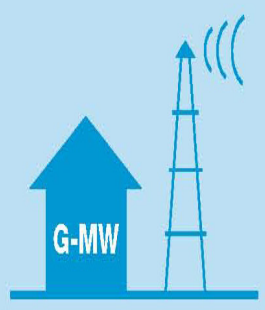

\section{STEP 3}

Radio Node Towers recerve the channel operation data fom the G-MW PMM system and forward on to automated chamel regulatotors and service points (meters) as needed.

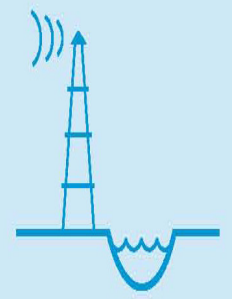

STEP 4

Automated channel regulators receive request, evaluate curent water levels in channel, compare with required channel operating levels and adust channel operating level to meet the order.

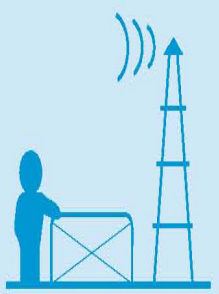

STEP 5

On-farm meters with remoteoperate functionality receive request from IPM through the Radio Node Towers and open at the conrest time.

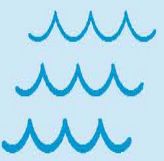

STEP 6

Irigation starts at time scheduled

and continues for the duration

requested by the cusstomer. Meters

and automated charnel regulators

continue to 'tak' to each other during

delivery to ensure water flow and

supply levels are maintained.

Figure 11: Process steps for placing, scheduling and delivering water. The IMA is Goulburn-Murray Water Authority (G-MW). 


\section{Conclusions}

The experience in Victoria Australia clearly demonstrates that with the right modernization strategy involving a mix of investment in cutting edge technology and infrastructure, large gravity irrigation systems can be made to perform well. Performance improvements are benefiting customers through greatly enhanced customer services and irrigation system managers and through enhanced management information systems and the ability to manage all aspects of water operations in real-time. Water savings brought about by large increases in efficiency of use of water for irrigation means that water saved is being transferred to meet the growing demands in the urban and industrial sectors and to meet environmental requirements and well as improving the security of irrigation allocations.

\section{References}

[1] United Nations Population Division www.unpopulation.org

[2] White Paper Securing Our Water Future Together, Victorian State Government Department of Sustainability and Environment - June, 2004 ISBN 174106826 6. www.ourwater.vic.gov.au/resources/library/a_z? root node_selection $=4566 \&$ result 4567 result_page $=\mathrm{S}$

[3] The Department of Sustainability and Environment (DSE) web-site www.dse.vic.gov.au/dse/index.htm. State water resources planning, implementation and management. (www.dse.vic.gov.au/dse/wcmn202.nsf/ Home+Page/592E2077307FBB0CCA256FE100095CDD?open)

[4] Northern Victoria Irrigation Renewals Project (NVIRP) (www.nvirp.com.au)

[5] Rubicon System Australia. www.rubicon.com.au

[6] Innovation in Irrigation, Australian Government, Department of Environment and Water Resources Publication, 2007 ISBN 064255370X www.nht.gov.au/irrigation

[7] Goulburn-Murray Water Authority (G-MWA) Customer Services WaterLINE portal www.g-mwater.com.au/customer-services/waterline 